\title{
Programa Menino do Dedo Verde: 23 anos integrando proteção social e cidadania ambiental
}

\author{
Janaine Voltolini de Oliveira ${ }^{1}$, John Eric Lemos de Amorim², \\ Maria Clélia Lustosa Costa $^{3}$ e Luzia Voltolini ${ }^{4}$
}

\footnotetext{
1 Doutoranda em Geografia pela Universidade Federal do Ceará, Mestre em Políticas Públicas pela Universidade Federal do Maranhão. Professora do curso de Serviço Social na Universidade Estadual de Roraima. E-mail: janainevoltolini@yahoo.com.br

2 Doutorando em Geografia pela Universidade Federal do Ceará, Mestre em Ciências Agrárias pela Universidade Federal do Amazonas. Professor do curso de Agronomia na Universidade Estadual de Roraima. E-mail: john.amorim@hotmail.com

3 Professora Associada do Departamento de Geografia da Universidade Federal do Ceará. E-mail: clelialustosa@gmail.com

4 Professora do curso de Pedagogia na Universidade Estadual de Roraima. E-mail: luvoltolini@hotmail.com
}

\begin{abstract}
RESUM0: O Programa Menino do Dedo Verde, junção das políticas de assistência social e meio ambiente atende adolescentes em situação de risco e vulnerabilidade social em Boa Vista/Roraima com foco na proteção social, fortalecimento de vínculos familiares e protagonismo juvenil com ênfase na cidadania ambiental, tendo o desafio do engajamento na construção de uma cultura formadora de atitudes de cidadania ecológica, supondo o sentido de responsabilidade ética e social que considere a solidariedade e a justiça ambiental como faces de uma sociedade justa e ambientalmente orientada para a geração de novas predisposições comportamentais, reavaliação de valores e visão de mundo.
\end{abstract}

Palavras-chave: adolescentes; vulnerabilidade social; meio ambiente; cidadania ambiental; protagonismo juvenil.

\begin{abstract}
The Menino do Dedo Verde Program , joining the social welfare policies and environment meets adolescents at risk and social vulnerability in Boa Vista / Roraima focused on social protection, strengthening family ties and youth leadership with an emphasis on environmental citizenship, and the challenge of engagement in the construction of a formative culture of ecological citizenship attitudes, assuming the sense of ethics and social responsibility to consider the solidarity and environmental justice as faces of a just society and environmentally oriented for generating new behavioral predispositions, revaluation values and world view .
\end{abstract}

Keywords: adolescents; social vulnerability; environment; environmental citzenship; youth leadership.

Sumário: 1 Introdução - 2 Conceituando assistência social e educação ambiental; 2.1 Assistência Social: uma política territorial de enfrentamento à pobreza; 2.2 Educação ambiental - EA - 3 Programa social "Menino do Dedo Verde": breve histórico; 3.1 Atividades realizadas; 3.2 Proposta de matriz curricular - Considerações Finais; Referências.

\section{INTRODUÇÃO}

Toda ação educativa voltada para a formação de consciência da preservação do meio

Planeta Amazônia: Revista Internacional de Direito Ambiental e Políticas Públicas 
ambiente e para a tomada de decisões sobre questões ambientais pode ser considerada como educação ambiental. 0 processo de aprendizagem por meio de projetos alinha-se a uma estratégia de trabalho transversal, uma vez que elementos de variadas disciplinas se encontram num mesmo contexto, favorecendo a troca de informações e um melhor aproveitamento dos conteúdos.

0 trabalho interdisciplinar, presente no Programa Menino do Dedo Verde representa a possibilidade de ordenar conteúdos e políticas públicas capazes de reger a transformação da sociedade, já que considera aspectos sociais, ambientais, culturais e políticos que respondem diretamente aos anseios humanos.

\section{CONCEITUANDO ASSISTÊNCIA SOCIAL E EDUCAÇÃO AMBIENTAL}

Para melhor compreensão da concepção do programa Menino do Dedo Verde, da Prefeitura M unicipal de Boa Vista/RR faz-se necessário recorrermos às políticas públicas que 0 alicerçam. Seu sustentáculo está pautado nas políticas de Assistência Social e Educação Ambiental, sendo que a primeira foi instituída na Constituição Federal de 1988 e compõe, junto à saúde e a previdência social, o tripé da Seguridade Social que, por sua vez, está definida no título Da Ordem Social, que tem como base o primado do trabalho, e como objetivo, o bemestar e a justiça social (BRASIL, 1988).

\subsection{Assistência Social: uma política territorial de enfrentamento à pobreza}

Segundo a Constituição Federal de 1988,
Art. 203. A assistência social será prestada a quem dela necessitar, independente- mente de contribuição à seguridade social, e tem por objetivos:
I - a proteção à família, à maternidade, à infância, à adolescência e à velhice;
II - 0 amparo às crianças e adolescentes carentes;
III - a promoção da integração ao mercado de trabalho;
IV - a habilitação e reabilitação das pessoas portadoras de deficiência e a promoção de sua integração à vida comunitária;
$\mathrm{V}$ - a garantia de um salário-mínimo de benefício mensal à pessoa portadora de defi- ciência e ao idoso que comprovem não possuir meios de prover à própria manuten- ção ou de tê-la provida por sua família, conforme dispuser a lei (idem).

A Lei no 8.742, de 7 de dezembro de 1993, mais conhecida como LOAS (Lei Orgânica da Assistência Social, dispõe sobre a organização da Assistência Social e vem regulamentar o disposto no Art. 203 da Constituição Federal.

Art. $1^{\circ}$ A assistência social, direito do cidadão e dever do Estado, é Política de Seguridade Social não contributiva, que provê os mínimos sociais, realizada através de um conjunto integrado de ações de iniciativa pública e da sociedade, para garantir o atendimento às necessidades básicas.

Art. 2ํㅡ A assistência social tem por objetivos: 
I - a proteção social, que visa à garantia da vida, à redução de danos e à prevenção da incidência de riscos, especialmente:

a) a proteção à família, à maternidade, à infância, à adolescência e à velhice;

b) 0 amparo às crianças e aos adolescentes carentes;

c) a promoção da integração ao mercado de trabalho; (...)

II - a vigilância socioassistencial, que visa a analisar territorialmente a capacidade protetiva das famílias e nela a ocorrência de vulnerabilidades, de ameaças, de vitimizações e danos; (...)

A organização da LOAS se dá por meio dos benefícios (de Prestação Continuada ou Eventuais), serviços, programas e projetos de assistência Social e, nestes últimos, é que a preservação do meio ambiente está situada.

No texto da política, ao tratar dos Projetos de Enfrentamento da Pobreza, destaca a preservação ambiental como fonte de possíveis ações voltadas à melhoria da qualidade de vida das populações.

Art. 25. Os projetos de enfrentamento da pobreza compreendem a instituição de investimento econômico-social nos grupos populares, buscando subsidiar, financeira e tecnicamente, iniciativas que Ihes garantam meios, capacidade produtiva e de gestão para melhoria das condições gerais de subsistência, elevação do padrão da qualidade de vida, a preservação do meio ambiente e sua organização social.

Ressalta-se que, as ações da assistência social abrangem todo o país, num sistema descentralizado e participativo (Art. 6ㅇ) ), cabendo à União, aos Estados, ao Distrito Federal e aos Municípios, fixar suas respectivas políticas, observados os princípios e diretrizes da Lei (Art. 8 ). Ainda, que as ações nas três esferas de governo devem se realizar de forma articulada, cabendo à União a coordenação e as normas gerais e aos demais, a coordenação e execução dos programas (Art. 11), cabendo ainda "formular e co-financiar, além de monitorar, avaliar, capacitar e sistematizar informações" (PNAS, 2004, p. 43).

A análise territorial se justifica em razão do Brasil ser um país com alta densidade populacional e, ao mesmo tempo, demasiado heterogêneo e desigual socioterritorialmente, ou seja, "o princípio da homogeneidade por segmentos na definição das prioridades de serviços, programas e projetos torna-se insuficiente frente as demandas de uma sociedade marcada pela alta desigualdade social" (idem), exigindo, portanto "agregar ao conhecimento da realidade a dinâmica demográfica associada à dinâmica socioterritorial em curso" (ibidem), considerando ainda que muitas das ações da assistência social impactam outras políticas ou são impactadas por elas.

Importante destacar que a discussão do território somente passa a ser compreendido como elemento essencial e imprescindível à execução da política de assistência social a partir da Política Nacional de Assistência Social (PNAS), aprovada pelo Conselho Nacional de Assistência Social por meio da Resolução no 145, de 15 de outubro de 2004, publicada no Diário Oficial da União em 28 de outubro de 2004.

A consolidação da PNAS veio fortalecer a política de assistência social como direito, 
desencadeando um processo de discussão e ressignificação, voltadas à efetivação do Sistema Único de Assistência Social (SUAS). Suas bases partem do conhecimento do Estado brasileiro e consideram "que o modelo de desigualdade socioterritorial do país se reproduz na dinâmica das cidades" (PNAS, p. 17), sendo necessário "um panorama desses territórios, espaços privilegiados de intervenção da política de assistência social" (idem).

Para tanto, realizou-se análise situacional global, sugerindo que as informações fossem confrontadas com dados locais. Os dados foram apresentados de acordo com a divisão proposta para os municípios, quais sejam: Municípios pequenos 1 - com população até 20.000 habitantes, Municípios pequenos 2 - com população entre 20.001 até 50.000 habitantes, Municípios médios - com população entre 50.001 até 100.000 habitantes, Municípios grandes - com população entre 100.001 até 900.000 habitantes e Metrópoles - com população superior a 900.000 habitantes.

Além de aspectos demográficos, com população total e classificação dos municípios segundo número de habitantes (em áreas rurais e urbanas), foram considerados: concentração da indigência e da pobreza, famílias chefiadas por pessoas do sexo feminino, proteção social a crianças, adolescentes e jovens em relação a educação, ocupação (inclusive trabalho infantil) e gravidez, equidade, concentração de população idosa com mais de 65 anos, pessoa com deficiência, entre outros como gasto e investimento na política.

\subsection{Educação ambiental - EA}

No cenário atual, compreender a EA requer o entendimento de uma variedade de leituras, todas fundamentadas em diferentes posturas políticas e visões de mundo - e, por consequência, de modelo de sociedade, uma vez que é possível que se esbarre, a todo momento, com lógicas, ideologias, ações, valores e interesses diferenciados.

De acordo com Rodriguez e Silva (2013, p. 175), "há múltiplas definições sobre o conceito de educação ambiental. A maioria delas frisa que é um processo de aprendizagem e comunicação (...) dos seres humanos com o ambiente". Para os autores, esta compreensão se faz necessária pois a humanidade passa por uma crise civilizatória de caráter ambiental, que afeta profundamente os sistemas locais e regionais e seus grupos sociais (idem) e a educação ambiental, embora marcada por uma concepção reducionista, fragmentada, naturalista e conservacionista, surge com um papel fundamental na construção do futuro.

A EA surge em um terreno marcado por uma tradição naturalista. Superar essa marca, mediante a afirmação de uma visão socioambiental, exige um esforço de superação da dicotomia entre natureza e sociedade, para poder ver as relações de interação permanente entre a vida humana social e a vida biológica da natureza (CARVALHO, 2006, p. 37).

Lima (2005), ao traçar as diferenças entre a tendência conservadora e a tendência emancipatória de educação ambiental, reconhece "o meio ambiente como base de sustentação para as sociedades humanas e não-humanas" e atenta para a necessidade de se politizar 
a questão ambiental, que, para o autor, "significa, em primeiro lugar, compreender e tratar os recursos naturais como bens coletivos e indispensáveis à vida e sua reprodutibilidade e 0 acesso a esses recursos como um direito público e universal" (idem).

Ao tratar os temas de educação, cidadania e justiça ambiental, Carvalho $(2006$, p. 163) afirma que, "do ponto de sua dimensão político-pedagógica, a EA poderia ser definida, lato sensu, como uma educação crítica voltada para a cidadania", devendo, portanto, "fornecer elementos para a formação de um sujeito capaz tanto de identificar a dimensão conflituosa das relações sociais que se expressam em torno da questão ambiental quanto de posicionarse diante desta" (idem).

\begin{abstract}
Para tanto, a EA deve auxiliar-nos em uma compreensão do ambiente como um conjunto de práticas sociais permeadas por contradições, problemas e conflitos que tecem a intrincada rede de relações entre os modos de vida humanos e suas formas peculiares de interagir com os elementos físico-naturais de seu entorno, de significálos e manejá-los.(...) Uma retrospectiva histórica mostra-nos quanto tem sido difícil estabelecer um pacto de convivência pacífica entre os seres humanos, o ambiente e os interesses dos diferentes grupos sociais sobre 0 direito e 0 acesso aos bens e recursos ambientais e sobre suas formas de uso. (...) (CARVALHO, 2006, p. 163-164).
\end{abstract}

Assim, é justamente na aposta da formação de novas atitudes e posturas cidadãs, bem como, no investimento de políticas públicas voltadas à preservação ambiental e à sustentabilidade capazes de construir "valores sociais, conhecimentos, habilidades, atitudes e competências voltadas para a conservação do meio ambiente, bem de uso comum do povo" (Lei 9.705 de 27/4/1999) que surge o programa Menino do Dedo Verde, cujas ações reforçam a importância da educação ambiental e, os resultados, aliados também às outras políticas, ratificam sua capacidade de transformação social como veremos a seguir.

\title{
3 PROGRAMA SOCIAL “MENINO DO DEDO VERDE”: BREVE HISTÓRICO
}

A verdadeira educação ambiental deve ter como preocupação proteger não só as águas, 0 ar, as florestas, a flora, a fauna, mas também, os homens e as mulheres que, muitas vezes exatamente por reunirem todas as características que os tornam mais suscetíveis à injustiça ambiental - miséria, pobreza, situação de risco em todos os sentidos, principalmente falta de (in) formação - tornam-se ao mesmo tempo, vítimas e algozes do seu entorno (LEROY; PACHECO, 2006, p. 68-69).

Situado no horto municipal, anexo ao Parque Anauá, o Programa Social "Menino do Dedo Verde", formulado e executado pela Prefeitura Municipal de Boa Vista/Roraima por meio da Secretaria Municipal de Gestão Social - SMGS, responsável pelos benefícios, serviços, programas e projetos da política pública de assistência social, iniciou suas atividades há 23 anos, em 14/4/1993 (Figura 1), na gestão da prefeita Teresa Surita.

Atende adolescentes e jovens na faixa etária de 14 a 18 anos, de ambos os sexos, que ingressam a partir de seleção, por equipe multiprofissional composta por assistente social, 
pedagogo e psicólogo. A seleção se dá por meio de análise de cadastros realizados pelas famílias em situação de risco e/ou vulnerabilidade social constantes do Cadastro Único da Assistência Social - CADÚnico, que contempla, entre outras coisas, informações socioeconômicas (composição familiar, renda, habitação e transporte), de acesso a saneamento básico, educação e profissionalização.

0 programa foi gestado com o objetivo de combater a evasão escolar, a gravidez não planejada, e o uso/abuso de drogas lícitas e ilícitas, o que seria alcançado por meio de incentivo à profissionalização, com cursos que trariam noções de educação e preservação ambiental, ações voltadas ao fortalecimento de vínculos familiares, oficinas e palestras sobre cuidados com a saúde bucal, sexual e reprodutiva, além de peças teatrais que tratam especificamente temas como uso de entorpecentes, trabalho infantojuvenil, exploração sexual, entre outros de interesse dos adolescentes.

Figura 1 - Aniversário do Projeto M enino do Dedo Verde

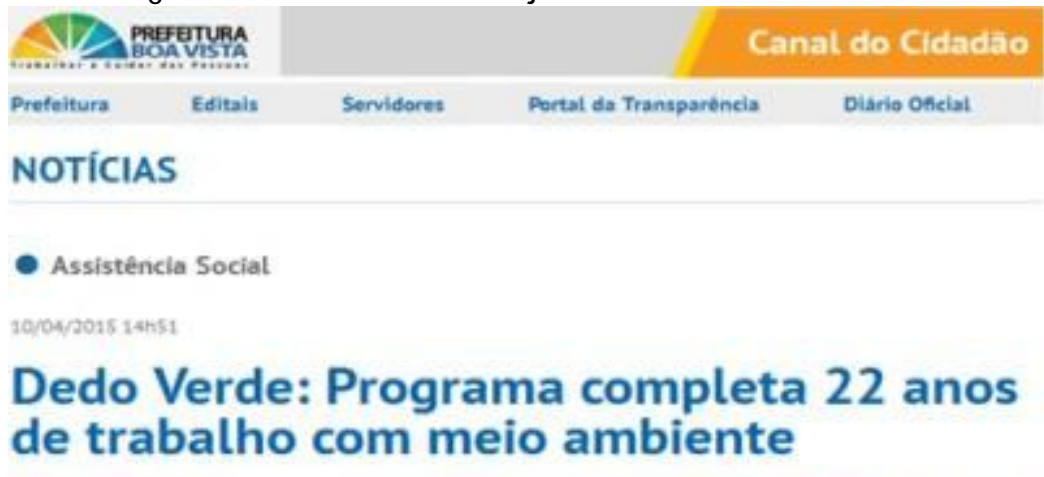

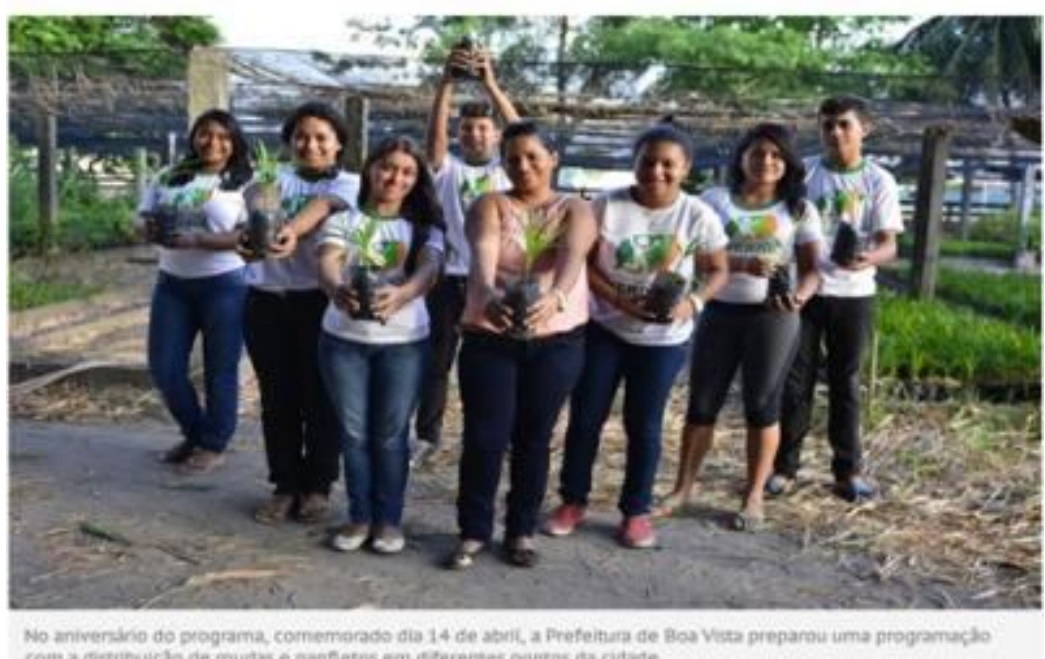

Fonte: http:// www.boavista.rr.gov.br/noticias/2015/04/dedo-verde-programa-completa-22-anos-de-trabalho-com-meioambiente. Acesso em 4/3/2016.

Como condicionalidades ao ingresso estão a matrícula e frequência em instituição de ensino e assiduidade e pontualidade no projeto. Por este motivo, o público frequenta o projeto em horário oposto ao das atividades escolares, divididos em turmas específicas de acordo com o desenvolvimento das atividades e disciplinas cursadas, como explica os itens 2.1 e 2.2 . 
Durante o período de permanência, fazem pelo menos 2 refeições, ou seja, no matutino recebe lanche e almoço e no vespertino, recebem lanche e jantar; a alimentação, nesse contexto, torna-se fator determinante para a manutenção de muitos meninos e meninas, uma vez que, devido a situação socioeconômica, muitos afirmavam, à época da pesquisa de campo, não ter condições de, em casa, fazer pelo menos 3 refeições diárias. Tal ação dava-se em parceria com a Secretaria M unicipal de Educação e Cultura - SM EC, por meio da cessão de parte da merenda escolar.

Ainda pensando na permanência, motivação e complementação de renda das famílias, o projeto disponibiliza uniforme, vale-transporte e, atualmente, atende 100 adolescentes cujas famílias percebem $\mathrm{R} \$ 180,00$ mensais de benefício de transferência de renda. As categorias profissionais envolvidas no acompanhamento são: serviço social, psicologia, pedagogia, biologia, engenharia agronômica, cozinheiro, monitor e técnico agrícola.

\subsection{Atividades realizadas}

O programa Menino do Dedo Verde funciona de segunda-feira a sexta-feira, sempre em horário oposto às atividades escolares. De segunda-feira a quarta-feira são executadas atividades de campo, de acordo com a disciplina de cada turma, como veremos a seguir na discussão da matriz curricular; cada disciplina tem duração de um semestre (não tendo definida uma carga horária específica) e seu término deve coincidir com o início das férias escolares. Entre as atividades desenvolvidas estão a construção, manejo e manutenção de jardins no horto municipal, atividades agronômicas e agrícolas básicas, construção de hortas, manejo de olerícolas, culturas perenes e semi-perenes e identificação, cuidado e uso de plantas medicinais, além de atividades voluntárias voltadas à comunidade, garantindo 0 eixo integrador de conhecimento e respeito ao meio ambiente e cidadania (Anexo 2). À época da pesquisa de campo, os serviços prestados à comunidade eram destinados à manutenção de jardins de órgãos públicos municipais e de rotatórias da cidade.

As quintas-feiras são destinadas às palestras educativas, sendo que duas vezes por mês o tema, obrigatoriamente, deve ser educação ambiental e fica a cargo da Secretaria Municipal de Meio Ambiente e Assuntos Indígenas, que trata de temas como tráfico de animais, características dos resíduos sólidos, reciclagem e reutilização de materiais, preservação dos rios, da fauna, flora, vegetação, entre outros. Intercalando com o calendário supracitado, os temas tratados são cidadania, saúde sexual e saúde reprodutiva, doenças sexualmente transmissíveis, uso e abuso de substâncias psicoativas, protagonismo juvenil, cultura de paz e da não violência, por exemplo. Às sextas-feiras são realizadas atividades de canto coral e dança, grupo de hip-hop, desportivas e de lazer, com brincadeiras, jogos, teatro, cinema, gincanas e vivência de datas comemorativas (Figuras 2, 3, 4 e 5). 
Figura 2 - Atividades realizadas no Programa M enino do Dedo Verde

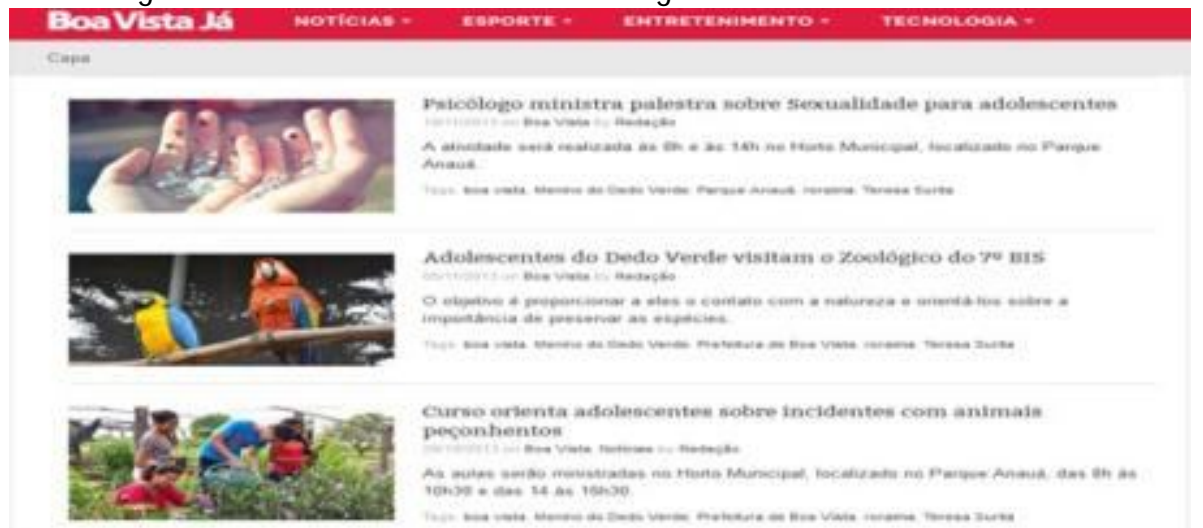

Fonte: http://boavistaja.com/tag/menino-do-dedo-verde/. Acesso em 4/3/2016.

Figura 3 - Atividades realizadas no Programa M enino do Dedo Verde

BoaVista Já noticias - esporte - entretenimento - TECNOLOGIA-

Capa

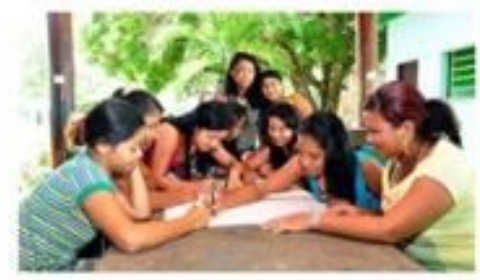

Adolescentes serão protagonistas para preservação ambiental

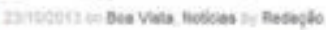

Mesino do Dedo Verde. Come parte da gade de athidades do programa toda segundateira os abolescertes panticioam de oficinas de Educacab? Ambiental

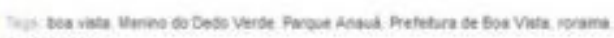
Teresa surts

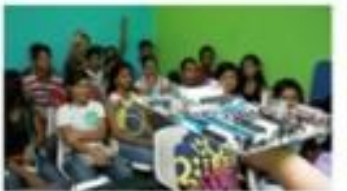

Menino do Dedo Verde: Prefeitura inclui aulas de Informática

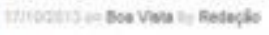

As aulas foram inseridas na grade be atvidades evisam melhorar a formaçalo dos adolescentes.

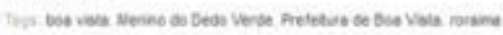

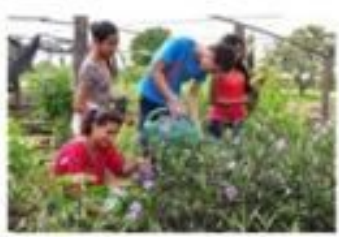

Aula de mústca é inserida no programa Dedo Verde

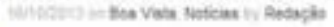

As atididades de pograma acomecem no Herto Municigal. ne Parque Arava

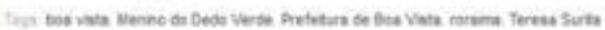

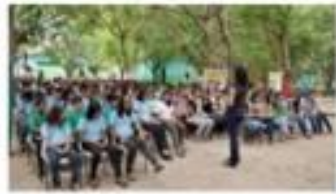

Estão sendo realizadas atividades educativas no Horto Municipal de Boa Vista

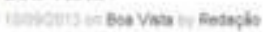

Progamaça conta com palestas apresentaçes culturas + concursos

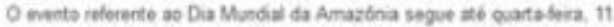

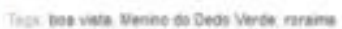

Fonte: http://boavistaja.com/tag/menino-do-dedo-verde/. Acesso em 4/3/2016. 
Figura 4 - Atividades realizadas no Programa M enino do Dedo Verde

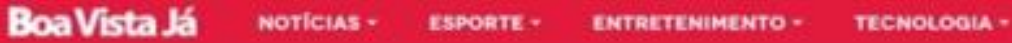

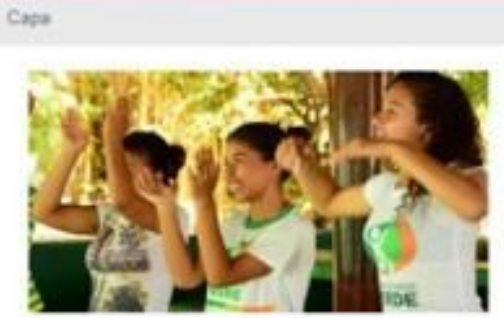

Dedo Verde: Adolescentes participam de oficina de dança

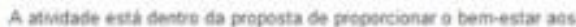
integrantes do projeste

Integrantes do Dedo Verde visitam teatro e preparam apresentaçào

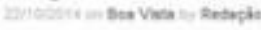

A idela e incentivar es joves sobre culura e ampla o discirse sobe prevença as drogas

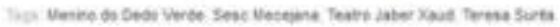

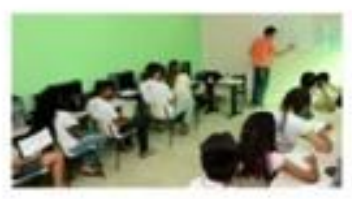

Adolescentes do programa Dedo Verde contam com aulas de inglês

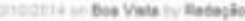

Mass de 45 alunes estiba aprestende a nowa lingua tods sextafeira. nas dependincias do programa, localizado no Parave Anaus

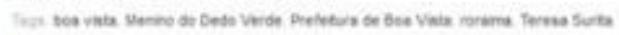

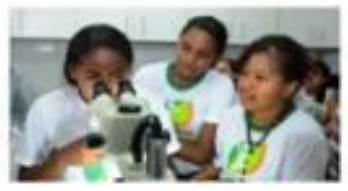

Integrantes do Dedo Verde visitam Embrapa

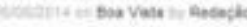

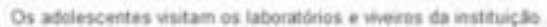

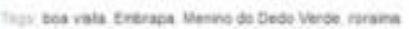

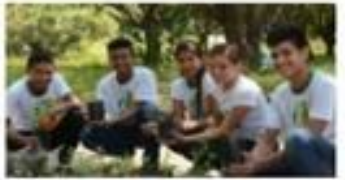

Prefeitura investe na alimentaçâo de integrantes do Programa Dedo Verde

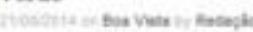

Os jorens pasticioam de ofcinas de portugets botarica + teanio

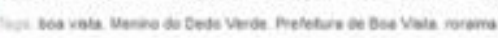

Fonte: http:// boavistaja.com/tag/menino-do-dedo-verde/. Acesso em 4/3/2016. 
Figura 5 - Atividades realizadas no Programa M enino do Dedo Verde

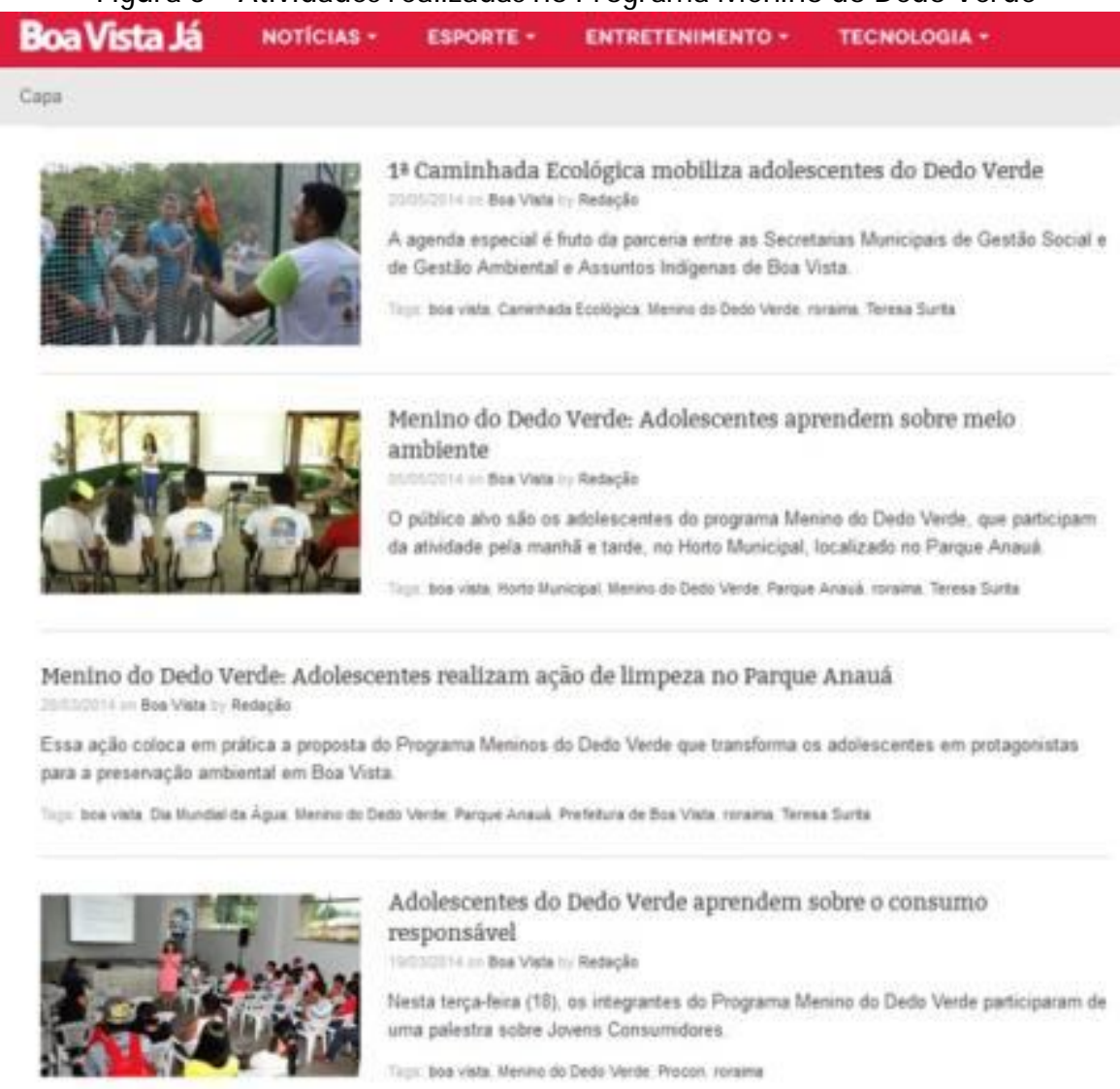

Fonte: http://boavistaja.com/tag/menino-do-dedo-verde/. Acesso em 4/3/2016.

Ao final de cada semestre, são aplicadas avaliações teóricas e práticas, tendo o aluno que obter aproveitamento mínimo de $50 \%$ nas aulas para que possa avançar para a próxima disciplina. Todos os integrantes do programa tem a oportunidade de aprender todas as disciplinas, sendo a rotatividade das turmas parte do planejamento das ações.

\subsection{Proposta de matriz curricular}

É necessário que haja uma criticidade na educação ambiental, capaz de oferecer uma "proposta voltada para um processo educativo desvelador e desconstrutor dos paradigmas da sociedade moderna com suas "armadilhas" e engajado no processo de transformações da realidade socioambiental, construtor de novos paradigmas constituintes de e constituídos por uma nova sociedade ambientalmente sustentável e seus sujeitos" (CARVALHO, 2006, p. 26).

Até 2006, o projeto não havia definido as atividades numa matriz curricular e os adolescentes eram acompanhados sem que houvesse um planejamento mais direcionado nas ações - objetivos, ementas, plano de ensino, ferramentas, insumos, monitoramento e avaliação, metas e prazos.

Diante dessa lacuna, surgiu a proposta de construção de uma matriz curricular que pu- 
desse nortear o trabalho da equipe técnica, trazendo com clareza de objetivos, métodos e metodologias o que seria executado ao longo de cada semestre de trabalho, bem como, explicitando recursos necessários - físicos, humanos, equipamentos e insumos. Tal proposta visava não apenas consolidar o projeto social e sua concepção centrada na atividade ocupacional e de construção de identidades e valores morais e éticos, como também visava agregar conhecimentos relativos ao meio ambiente, educação e preservação dos recursos naturais e sustentabilidade, além de favorecer a aprendizagem e a profissionalização, gerando maior autonomia e facilitando a inserção no mercado de trabalho (Figura 6).

Desta forma, as oito disciplinas expostas na tabela abaixo já faziam parte do dia a dia do projeto e outras estavam (em 2006) em fase de experimentação e aprimoramento de acordo com a realidade e a necessidade do programa, cabendo à Secretaria responsável decidir por sua continuidade ou descontinuidade com base nos recursos necessários para sua implantação.

Figura 6 - Programa Dedo Verde atende adolescentes em situação de vulnerabilidade social Dedo Verde

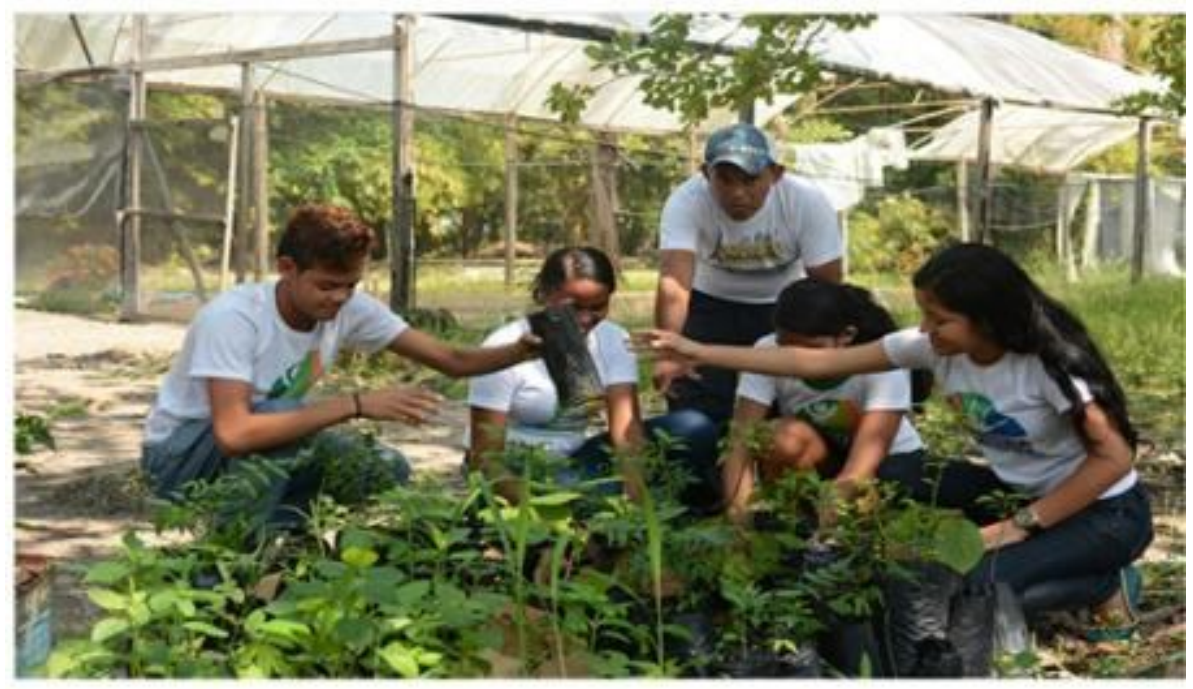

Proteçào social, defesa de direitos, prevença de riscos, fortalecimento dos vinculos sociais e familiares e do protagonismo juvenil com enfase na cidadania ambiental. Salo estes os objetivos das açóes desenvolvidas pelo programa Dedo Verde, que atende adolescentes com idades entre 14 e 18 anos, em situaçào de vulnerabitidade sociat.

\begin{abstract}
Entre as atividades eståo açòes voltadas para a cuttura, como oficinas de música e teatro, práticas esportivas e recreaçăo, oficinas de educaçąo ambiental, produçáo de plantas medicinais, flores tropicais e húmus, além de reforço escolar, informática e clube de leitura. Hà ainda a participaçảo em eventos como Feira Sebrae, Natal, arraial e passeios ao cinema e aos igarapés.
\end{abstract}

\begin{abstract}
Os jovens também participam de açōes educativas em que sâo trabathados aspectos relacionados à saude - atendimento médico, odontológico, oftalmológico, palestras pertinentes e primeiros socorros.
\end{abstract}

Atualmente o programa atende 100 adolescentes, que recebem uma bolsa no valor de RS180, vale-transporte, lanche e refeiçăo. Eles elaboram um cademo de memória (narrativa autobiografica) e, ao completarem 18 anos, sào preparados para deixar o Dedo Verde por meio de uma capacitaçâo em uma tinha de produçâo sustentável.

Fonte: http://www.boavista.rr.gov.br/canal-do-cidadao-projetos/dedo-verde. Acesso em 4/3/2016.

Planeta Amazônia: Revista Internacional de Direito Ambiental e Políticas Públicas 
Tabela 1 - Disciplinas do Programa M enino do Dedo Verde

\begin{tabular}{|c|c|c|}
\hline Disciplina & Objetivo & 0 que é ensinado \\
\hline $\begin{array}{l}\text { Agricultura } \\
\text { ecológica }\end{array}$ & $\begin{array}{l}\text { Capacitar para } \\
\text { práticas agroeco- } \\
\text { lógicas e abaste- } \\
\text { cer o projeto com } \\
\text { material orgânico } \\
\text { (adubo). }\end{array}$ & $\begin{array}{l}\text { Importância da agricultura ecológica na produção de hortaliças; } \\
\text { Cuidados básicos com o solo, técnicas de compostagem e tratos culturais utilizados } \\
\text { para minimizar o efeito da agricultura no ecossistema; } \\
\text { Produção de biofertilizantes e utilização de micro-organismos; } \\
\text { Noções básicas de utilização de mecanismos agroecológicos no controle e combate de } \\
\text { pragas. }\end{array}$ \\
\hline $\begin{array}{l}\text { Cultivo } \\
\text { Protegido }\end{array}$ & $\begin{array}{l}\text { Capacitar para o } \\
\text { manejo de estufa } \\
\text { por meio de teo- } \\
\text { rias e experimen- } \\
\text { to demonstrativo } \\
\text { e para o cultivo } \\
\text { de hortaliças em } \\
\text { ambiente prote- } \\
\text { gido. }\end{array}$ & $\begin{array}{l}\text { Princípios e estrutura de uma estufa, escolha da área e critérios para instalação da } \\
\text { horta; } \\
\text { Limpeza da área de estufa: capinar, rastelar, recolher entulhos e resíduos; } \\
\text { Dimensionar a área da estufa: comprimento, largura e altura; } \\
\text { Preparar canteiros e revolver a terra: marcação, dimensionamento, preparo da terra e } \\
\text { adubação e substrato; } \\
\text { Preparar o canteiro para a sementeira e acabamento; } \\
\text { Executar tratos culturais: cobertura morta e estaqueamento; } \\
\text { Trabalhar com adubação orgânica: manejo e equilíbrio de bases; } \\
\text { Vantagens econômicas nesse tipo de manejo: economia da água, utilização e conser- } \\
\text { vação de ferramentas agrícolas e insumos. }\end{array}$ \\
\hline $\begin{array}{l}\text { Educação } \\
\text { ambiental e } \\
\text { cidadania }\end{array}$ & & $\begin{array}{l}\text { Educação ambiental: conceito, importância, preservação, reciclagem, riscos e danos } \\
\text { para a sociedade provocados pela poluição do ar e do meio ambiente; } \\
\text { Características e efeitos dos principais poluentes atmosféricos, controle biológico e } \\
\text { desenvolvimento sustentável; } \\
\text { Princípios da educação para sociedades sustentáveis, responsabilidade global e biodi- } \\
\text { versidade; } \\
\text { Paisagens naturais e patrimônio cultural: conservação e recuperação da biodiversida- } \\
\text { de, riscos e ameaças, água, ar, desmatamento, lixo, defesa do patrimônio natural e } \\
\text { cultural, florestas e desmatamento; } \\
\text { Cidadania: conceito, educação ambiental como educação crítica para a cidadania, } \\
\text { processo de construção da cidadania no Brasil; } \\
\text { Ecologia: conceito, subdivisões da ecologia, biosfera, condições para a existência da } \\
\text { biosfera; } \\
\text { Nutrição e respiração dos seres vivos: conceito, seres autótrofos e heterótrofos, pro- } \\
\text { cessos de nutrição, nutrição autótrofa, quimiossinteses, nutrição heteritrófica, respi- } \\
\text { ração, suprimento e demanda de energia, respiração aeróbica, respiração anaeróbica; } \\
\text { Ecossistema: conceito, dinamismo das biocenoses, homeostase da biocenose, condi- } \\
\text { ções ambientais do ecossistema, características do ecossistema, comparação entre } \\
\text { estrutura geral de um ecossistema terrestre e outro aquático, equilíbrio dos ecossis- } \\
\text { temas, fluxo de energia, pirâmides energéticas, as comunidades terrestres, as comu- } \\
\text { nidades marinhas, ambientes marinhos, zona litorânea, nerítica, abissal e pelágica, as } \\
\text { comunidades de água doce, os rios, os lagos e as lagoas; } \\
\text { Ciclo da matéria: conceito do ciclo biogeoquímico, ciclos gasosos, ciclos sedimentares, } \\
\text { ciclo da água e ciclo do fósforo; } \\
\text { Explosão demográfica: conceito, causas do crescimento populacional, distribuição } \\
\text { geográfica das populações, aumento populacional e desequilíbrios gerados, poluição, } \\
\text { principais fontes de poluição e natureza dos poluentes, poluição das águas e suas } \\
\text { consequências, poluição do ar, do solo, sonora e radiativa; } \\
\text { Política Nacional do M eio Ambiente e outras leis. }\end{array}$ \\
\hline Horticultura & $\begin{array}{l}\text { Capacitar para o } \\
\text { preparo da lavou- } \\
\text { ra em pequena }\end{array}$ & $\begin{array}{l}\text { Importância da horticultura, escolha da área para desenvolvimento da lavoura; } \\
\text { Definição e amostra de solos para trabalhar na lavoura; } \\
\text { Preparo da área de forma mecânica e manual, demarcação, adubação e calagem; }\end{array}$ \\
\hline
\end{tabular}

Planeta Amazônia: Revista Internacional de Direito Ambiental e Políticas Públicas

https://periodicos.unifap.br/index.php/planeta $\quad$ ISSN 2177-1642 Macapá, n. 8, p. 153-167, 2016




\begin{tabular}{|c|c|c|}
\hline & $\begin{array}{l}\text { escala, sobre as } \\
\text { culturas que se- } \\
\text { rão desenvolvi- } \\
\text { das. }\end{array}$ & $\begin{array}{l}\text { Escolha do material de propagação - semente e estaca; } \\
\text { Manejo de ferramentas e equipamentos (esmeril elétrico, facão, lima, bota, luva, } \\
\text { pulverizador, serrote, tesoura de poda, martelo) e insumos (calcário, esterco de gado } \\
\text { e carneiro, fertilizante, palha de arroz, pó de serragem); } \\
\text { Implantação de culturas de campo - espaçamento e tamanho das covas; } \\
\text { Diagnóstico de pragas e doenças encontradas nas culturas; } \\
\text { Planejamento rural. }\end{array}$ \\
\hline Jardinagem & $\begin{array}{lr}\text { Capacita } & \text { para } \\
\text { implantação } & \text { e } \\
\text { manejo de jar- } \\
\text { dins. }\end{array}$ & $\begin{array}{l}\text { Desenvolver agroatividade na elaboração de jardins; } \\
\text { Aprender a importância da jardinagem - conceito e história, classificação - público, } \\
\text { econômico ou privado e sua caracterização - formal, informal, naturalista; } \\
\text { Coletar e catalogar plantas regionais; } \\
\text { Textura de solo, remoção de entulhos e ervas daninhas, adição de corretivos e nutri- } \\
\text { entes, acréscimo de areia, locação de plantas - grande porte e arbusto; } \\
\text { Nivelamento do solo, levantamento de necessidades, análise da área, dos elementos, } \\
\text { observação - sol, sombra, vento para seleção das espécies; } \\
\text { Plantio de árvores - altura, cova, adubação e irrigação, seleção de espécies, escolha } \\
\text { da grama (Batatais, São Carlos, Esmeralda e Bermuda) e manutenção do gramado; } \\
\text { Controle de pragas e doenças comuns em jardins; } \\
\text { Cerca viva, cálculo de terra preta e unidade de planta; } \\
\text { Utilização e conservação de equipamentos, instrumentos e insumos. }\end{array}$ \\
\hline Olericultura & $\begin{array}{l}\text { Capacita para a } \\
\text { implantação e } \\
\text { manejo de hortas } \\
\text { comunitárias. }\end{array}$ & $\begin{array}{l}\text { Classificação das hortas e hortaliças; } \\
\text { Noções básicas de solo; } \\
\text { Escolha da área, medição e preparo do terreno para o plantio das hortaliças; } \\
\text { Tratos culturais: adubar, ralear, capinar, fazer cobertura morta, tutoramento, escarifi- } \\
\text { cação, amarrio, desbrota, desbaste de frutos, condução de ramas, polinização, bran- } \\
\text { queamento, controle fitossanitário, adubação foliar, amontoa; } \\
\text { Controle de pragas e doenças: conceitos, tipos e métodos de controle. }\end{array}$ \\
\hline $\begin{array}{l}\text { Plantas } \\
\text { Medicinais }\end{array}$ & $\begin{array}{l}\text { Capacitar para a } \\
\text { produção, mane- } \\
\text { jo e utilização de } \\
\text { plantas medici- } \\
\text { nais. }\end{array}$ & $\begin{array}{l}\text { Tratos culturais, poda, irrigação e capina; } \\
\text { Controle de pragas com preparo e uso de inseticidas naturais; } \\
\text { Identificação de plantas tóxicas; } \\
\text { Conhecimento da importância das plantas medicinais, seu cultivo, nomes científicos e } \\
\text { populares; } \\
\text { Tipos de solo e cálculo da área de cultivo; } \\
\text { Métodos de secagem; } \\
\text { Identificação de espécies de plantas medicinais mais comuns no estado de Roraima e } \\
\text { resgate da herança cultural no uso das plantas medicinais; } \\
\text { Catalogar espécies de plantas medicinais. }\end{array}$ \\
\hline $\begin{array}{l}\text { Serviço } \\
\text { Comunitário } \\
\text { Externo - } \\
\text { oferecidos } \\
\text { sem custo } \\
\text { aos benefi- } \\
\text { ciários }\end{array}$ & $\begin{array}{l}\text { Realização de } \\
\text { serviços voluntá- } \\
\text { rios de implanta- } \\
\text { ção e manuten- } \\
\text { ção de jardins da } \\
\text { comunidade, } \\
\text { órgãos públicos } \\
\text { municipais, rota- } \\
\text { tórias e canteiros } \\
\text { pela cidade. }\end{array}$ & $\begin{array}{l}\text { Classificação, tratamento e disposição adequada do lixo, compostagem, aterro sanitá- } \\
\text { rio, incineração e manejo ideal; } \\
\text { Noções de jardinagem, histórico e conceito, classificação de jardim, procedimentos } \\
\text { básicos para construção de jardins; } \\
\text { Diagnóstico de necessidades do jardim, levantamento da área e dos elementos; } \\
\text { Noções básicas dos tipos de solo, construção ao sol e à sombra; } \\
\text { Trabalhar com equipamentos, instrumentos e insumos básicos para implantação e } \\
\text { manutenção de jardins (enxada, ancinho, facão, escarificador, vassoura, saco de lixo, } \\
\text { regador, tesoura de poda, pá grande, pá de jardim - para transplante). }\end{array}$ \\
\hline Vivericultura & $\begin{array}{l}\text { Capacitar para } \\
\text { elaboração, ma- } \\
\text { nejo e propaga- } \\
\text { ção de plantas }\end{array}$ & $\begin{array}{l}\text { Produção de mudas: importância econômica, êxodo rural, arborização; } \\
\text { Implantação de viveiro: conceito, escolha do local e tipo; } \\
\text { Construção do viveiro: cuidados, drenagem e ferramentas; } \\
\text { Cálculo da área e substrato; }\end{array}$ \\
\hline
\end{tabular}

Planeta Amazônia: Revista Internacional de Direito Ambiental e Políticas Públicas 
ornamentais em Reprodução de mudas: semeadura e estaquia;

viveiro. $\quad$ Identificação dos tipos de mudas produzidas em viveiros: ornamentais, frutíferas e florestais;

Seleção de espécies, catalogação e nomes científicos;

Tratos culturais: rega, adubação e limpeza;

Controle de pragas e doenças: mobilização do solo, adubação, poda, catação manual, controle biológico, químico e sintético;

Utilização e conservação de equipamentos, instrumentos e insumos.

Fonte: Tabela elaborada sob orientação da engenheira agrônoma Inaê Rocha Pereira, da coordenadora Roselany Maria M arques Pereira da Silva (2006) e com apoio do Prof. Dr. Flávio Corsini Lírio, da Universidade Federal de Roraima.

Importa ressaltar que as atividades de horticultura e olericultura tem, ainda, o objetivo de fornecer a complementação alimentar dos adolescentes com verduras ali cultivadas, como alface, cebola, cebolinha, coentro, couve, pimenta, pepino, quiabo, rúcula e tomate e fornecer alimentos aos alunos do programa, enriquecendo sua nutrição e a atividade de plantas medicinais tem como objetivo ainda o desenvolvimento de fonte alternativa de renda. Aqui, os adolescentes aprendem ainda sobre colheita (folhas, flores, raiz, casca), secagem e armazenamento, medidas preventivas para que se saiba quando não se deve misturar plantas, quando utilizar e para qual finalidade, métodos para uso interno/caseiro (xarope, tintura, extrato, chá, suco), métodos para uso externo (cataplasma, unguento, óleo, pomada simples, pasta, creme, loção e gel), dosagem e fórmula para uso externo (sabão, xampu, condicionador, desodorante).

Os insumos, equipamentos e utensílios utilizados estão incluídos, assim como nas demais disciplinas, no processo de aprendizagem.

\section{CONSIDERAÇÕES FINAIS}

Endossando as palavras de Carvalho (2006, p. 181), o grande desafio da EA é ir além da aprendizagem comportamental, engajando-se na construção de uma cultura cidadã e na formação de atitudes sustentáveis. Isso supõe a formação de um sentido de responsabilidade ética e social, considerando a solidariedade e a justiça ambiental como faces de um mesmo ideal de sociedade justa e ambientalmente orientada. A formação de atitudes passa pela predisposição de mudança de comportamentos isolados, face a um processo coletivo de amadurecimento de valores e visões de mundo mais permanentes.

Após vinte e três anos de funcionamento, o programa "Menino do Dedo Verde" se mantém como referência na região norte de trabalho realizado com adolescentes e jovens cujas famílias encontram-se em situação de risco e/ ou vulnerabilidade social, na perspectiva de superação da pobreza e profissionalização.

Os resultados positivos se dão, além da aprendizagem de diversos temas, expostos neste estudo, em virtude da constante preocupação com a melhoria do atendimento aos usuários, acesso à informação, alimentação de qualidade, obrigatoriedade de escolarização, convívio familiar e comunitário, valorização e protagonismo dos adolescentes e jovens, elevação da autoestima e participação em atividades de cultura, esporte e lazer. 
Tais oportunidades são capazes de transformar a vida das pessoas, tornando-os capazes de elaborar e concretizar projetos de vida, pois agregam, acima de tudo, sentimento de dignidade, responsabilidade, atitude e consciência crítica e cidadã.

\section{REFERÊNCIAS}

BRASIL. M inistério do Desenvolvimento Social e Combate à Fome, Secretaria Nacional de Assistência Social. Política Nacional de Assistência Social PNAS/ 2004 e Norma Operacional Básica do Sistema Único de Assistência Social NOB/ SUAS. Brasília: 2005.

BRASIL. Presidência da República, Casa Civil, Subchefia para assuntos jurídicos. Constituição da República Federativa do Brasil de 1988.

. Lei no 8.742, de 7 de dezembro de 1993. Dispõe sobre a Lei Orgânica de Assistência Social e dá outras providências.

CARVALHO, I. C. M. Educação ambiental: a formação do sujeito ecológico. 2.ed. São Paulo: Cortez, 2006.

LEROY, J. P.; PACHECO, T. Dilemas de uma educação em tempos de crise. In: LOUREIRO, C. F. B.; LAYRARGUES, P. P.; CASTRO, R. S. (Orgs.). Pensamento complexo, dialética e educação ambiental. São Paulo: Cortez, 2006.

LIMA, G. F. C. Crise ambiental, educação e cidadania: os desafios da sustentabilidade emancipatória. In: LOUREIRO, C. F. B.; LAYRARGUES, P. P.; CASTRO, R. S. (Orgs.).Educação ambiental: repensando o espaço da cidadania. 3. ed. São Paulo: Cortez, 2005.

RODRIGUEZ, J. M. M.; SILVA, E. V. Educação Ambiental e Desenvolvimento Sustentável: problemas, tendências e desafios. Fortaleza: Edições UFC, 2013.

Artigo recebido em 26 de agosto de 2016.

Aprovado em 31 de dezembro de 2016. 